\title{
Comunicação ao plural: teorias, métodos e perspectivas
}

\author{
Paolo Demuru
}

BARRICHELLO, E. M. R.;

RUBLESCKI, A. (orgs).

Pesquisa em Comunicação:

olhares e abordagens.

Santa Maria, Facos-UFSM,

232 p., 2014.

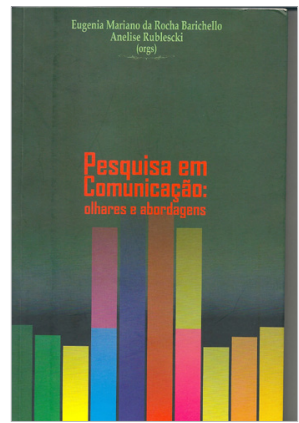

Resumo: O livro oferece uma panorâmica das atuais perspectivas e abordagens de pesquisa no campo da comunicação. Transitando entre diversos objetos e disciplinas - semiótica, jornalismo, antropologia, etc. - os nove textos aqui reunidos trazem questionamentos importantes a respeito das metodologias utilizadas pelos pesquisadores da área. Além de sua contribuição para a discussão metodológica, destaca-se, nesta resenha, um implícito posicionamento epistemológico, pelo qual não existem objetos definidos a priori, mas sim maneiras multíplices de construí-los e interrogá-los.

Palavras-chave: comunicação; metodologia; pluralidade.

Abstract: Plurality in communication: theories, methods and perspectives - The book provides an overview of current perspectives and approaches in the field of communication. Addressing different objects and moving through different areas - semiotics, journalism, anthropology, etc. - this collection of nine texts raises important questions about the methods used by researchers. In addition to its contribution to the debate on methodology, this review highlights an implicit epistemological assumption, according to which there are no aprioristically defined objects, but rather, multiple ways of building them and questioning them.

Keywords: communication; methodology; plurality. 
A força das ciências da comunicação reside em sua identidade plural: na multiplicidade de teorias, na polifonia de métodos e no caleidoscópio de perspectivas que elas envolvem e proporcionam. É essa a impressão que se tem após virar a última página de Pesquisa em Comunicação: olhares e abordagens, coletânea de nove textos organizada por Eugênia Mariano da Rocha Barrichello e Anelise Rublescki. Transitando entre diversos objetos e disciplinas, o livro oferece uma panorâmica das atuais práticas de pesquisa em comunicação, sem se limitar, contudo, a fotografar o estado da arte do campo. Longe disso, a obra projeta-se dinamicamente para o futuro, abrindo caminhos e avançando propostas tanto para o seu desenvolvimento científico, quanto para a sua consolidação institucional.

O primeiro artigo, de Eduardo Vizer e Helenice Carvalho, defende a necessidade de pensar as práticas de comunicação e os processos sociais como fenômenos inseparáveis e mutuamente constituídos. Duas são as hipóteses exploradas pelos autores: (i) a problematização teórica e metodológica dos processos comunicacionais se enriquece e se consolida quando associada a proposições efetivas sobre os processos sociais; (ii) é possível construir categorias de análise aplicáveis tanto aos processos sociais quanto a processos comunicacionais, discursivos e midiáticos.

No texto seguinte, Alexandre Rocha da Silva e João Fabrício Flores da Cunha refletem sobre as contribuições da semiótica peirceana para a prática de pesquisa em comunicação. A partir da releitura dos pressupostos epistêmicos do pragmaticismo, individuam-se três etapas fundamentais para a análise semiótica: (i) a descrição das condições e das possibilidades de existência dos signos; (ii) a investigação das diversas formas de raciocínio (abdução, dedução, indução); (iii) a construção de uma metodêutica que aborde, de maneira crítica, os métodos empregados na pesquisa científica. Ressalta-se a importância de uma perspectiva interdisciplinar, que combine a semiótica com outras teorias específicas - por exemplo: a teoria do cinema na análise de uma obra fílmica - para que "se possa elaborar uma investigação mais razoável de um determinado processo de signos" (p. 62). No entanto, apesar da coesão entre os preceitos teórico-epistemológicos da filosofia peirceana e as propostas apresentadas, sente-se a exigência de uma discussão mais ampla e profunda que indique caminhos mais concretos para evitar o risco, vislumbrado pelos próprios autores, de que a abordagem semiótico-pragmaticista se limite apenas a rotular "os objetos de sua análise como ícone, índice e símbolo" (p. 62), ou a definir um raciocínio enquanto abdutivo, dedutivo ou indutivo, o que acabaria por exemplificar e justificar a coerência interna da teoria mais do que ajudar a compreender as manifestações de sentido analisadas.

A semiótica - desta vez de matriz europeia - é também o cerne do artigo de Elizabeth Bastos Duarte e Maria Lília de Castro. Com base nas proposições de Algirdas Julien Greimas e Mikhail Bachtin: afirma-se a urgência, por um lado, de analisar os produtos midiáticos juntamente com os processos comunicativos e enunciativos que os moldam 
e, por outro lado, de rever e adequar os conceitos à luz da pertinência e dos objetivos da pesquisa. Levando ao extremo o raciocínio das autoras, poderíamos afirmar que a especificidade semiótica discursiva no estudo da comunicação consiste, como sugeriu Franciscu Sedda (2012), em praticar um "olhar estereoscópico" que articule descrições densas e detalhadas de determinados textos ou práticas midiáticas com análises cada vez mais vastas, que levem em conta suas relações intertextuais e interdiscursivas. Dito de outra forma, parafraseando Hjelmslev, trata-se de optar por um dúplice e correlato movimento de análise e catálise, em que a "descida analítica" rumo a descrição de um objeto especifico obriga o pesquisador a reconstruir, "por catálise", um sistema que seja coesivo em relação a este objeto (HJELMSLEV, 1975, p. 131).

O quarto artigo, de Mirian Quadros, Gabriela Assmann e Debora Cristina Lopez aborda a utilização e as derivações da Análise do Conteúdo em pesquisas da área de comunicação. A partir de um levantamento de dados focado na aplicação do método em 57 teses e dissertações defendidas em 2012, as autoras salientam e defendem a versatilidade da Análise do Conteúdo e seu uso em combinação com outras teorias, especialmente diante dos atuais volumes de dados.

Os dois textos sucessivos transitam entre comunicação e antropologia. A partir do questionamento da autoridade e da escrita etnográfica propostos por estudiosos como James Clifford, Juliana Loureiro de Oliveira e Virginia Pradelina da Silveira Fonseca os autores convidam a adotar uma postura critica e "de estranhamento" no campo de pesquisa em jornalismo, que problematize o lugar do pesquisador em sua relação com o "outro" e a "situacionalidade do conhecimento produzido" (p. 128). Por sua vez, apresentando os resultados do projeto "Inclusão Social via socialização online de Pessoas com Necessidade Especiais", Sandra Portella Montardo reflete sobre as peculiaridades da Netnografia e da Análise de Redes Sociais, oferecendo sugestões para repensar tanto a observação participante com relação às comunidades analisadas, quanto os caminhos para a construção do corpus e da pertinência da pesquisa.

O sétimo artigo, de Debora Cristina Lopes e Marisandra Rutilli, traça diretrizes metodológicas para compreender o newsmaking. A ideia central defendida pelas autoras é que "o fazer jornalismo e fazer ciência sobre jornalismo" devem ser entendidos como processos que caminham lado a lado, compartilhando métodos e ferramentas. Entre estes, ressaltam-se práticas como a observação, a entrevista, a pesquisa documental e o estudo de caso, comuns tanto à atividade jornalística quanto à investigação acadêmica.

Dando continuidade às proposições elaboradas na abertura do livro, Eduardo Vizer e Helenice Carvalho apresentam, no nono capítulo, uma proposta metodológica para a investigação do funcionamento de qualquer organização a partir de suas práticas e dispositivos materiais, técnicos, sociais, culturais e discursivos. De modo especial, concentram-se no desenvolvimento de um dispositivo para a análise e o diagnóstico sociocomunicacional que leve em conta as seguintes dimensões: (i) as práticas e 
as ações instrumentais, ou seja, as técnicas associadas à produção e à transformação dos recursos necessários para o funcionamento de uma comunidade ou de uma organização; (i) a estrutura política e as relações de poder internas e externas nas quais aquela se baseia; (iii) suas práticas cotidianas; (iv) a construção do espaço e do tempo; (v) os vínculos de associação interpessoal e afetiva; (vi) a dimensão da cultura, do imaginário, das narrações, das representações e dos rituais.

Encerrando o livro, Ana Cristina Machado da Silveira e Eugênia Mariano da Rocha Barrichello refletem sobre as condições de aprendizado do labor científico na área de comunicação, tecendo propostas finalizadas a despertar o espírito investigativo e a cultivar o manejo das técnicas e dos procedimentos das pesquisas, que contemplam a inserção de programas disciplinares específicos para a graduação, o período pré-TCC, o mestrado e o doutorado.

Como apontam as organizadoras na apresentação da obra, "se é o objeto que demanda o percurso metodológico em qualquer pesquisa, também é verdadeiro que há sempre múltiplos caminhos e olhares possíveis de acordo com a formação teórica e epistemológica dos autores" (p. 2). Ao lado da discussão detalhada sobre a especificidade de cada abordagem e perspectiva, talvez seja essa a maior contribuição dos textos aqui reunidos: lembrar que na pesquisa em comunicação não há objetos definidos a priori e sim maneiras diversas de construí-los e interrogá-los. Quanto mais elas dialogarem, maior será o ganho para o campo.

Paolo Demuru é doutor em Semiótica pela Universidade de Bologna (Itália). Desenvolve atualmente sua pesquisa de pós-doutorado no PPG Comunicação e Semiótica da PUC-SP, junto ao Centro de Pesquisas Sociossemióticas paolodemuru@gmail.com

\section{Referências}

HJELMSLEV, L. T. Prolegômenos a uma teoria da linguagem. São Paulo: Abril, 1975.

SEDDA, F. Imperfette Traduzioni. Roma: Nuova Cultura, 2012. 